\title{
Synthesis and Characterization of Cerium Oxide Nanoparticles using Sucrose as a Green Capping Agent and its application for Antibacterial and Humidity Sensor Studies
}

\author{
A.Mobeen and R. Sundaram* \\ PG and Research Department of Chemistry, Presidency College (Autonomous), Chennai 600 005, Tamil \\ Nadu, India. \\ *Corresponding author: drsundarampresidency@gmail.com
}

\begin{abstract}
Cerium oxide nanoparticles $\left(\mathrm{CeO}_{2} \mathrm{NPs}\right)$ were prepared by co-precipitation method using cerium chloride and sodium hydroxide $(\mathrm{NaOH})$ in presence of sucrose as a green capping agent. The obtained yellowish white powder was characterized via X-ray diffraction studies (XRD), transmission electron microscopy (TEM), Fourier transform infrared spectroscopy (FT-IR), X-ray energy dispersive spectroscopy (EDX), UV-Visible spectroscopy and photoluminescence (PL). The antibacterial activity of the synthesized nanoparticles were observed in two Gram-negative and one Gram-positive bacterial pathogens, which exhibits encouraging result and shows the zone of inhibition increased with concentration of the nanoparticles. The sensor measurement was carried out by observing linear decrease in dc resistance with relative humidity at different humidity environment $\left(\mathrm{RH}_{5 \%}\right.$ to $\left.\mathrm{RH}_{98 \%}\right)$. The response and recovery time and the sensitivity factor $\mathrm{S}_{\mathrm{f}}=2876$ was calculated. The results illustrates that the synthesized cerium oxide nanoparticles acts a good sensor element to apply in humidity sensor and antibacterial applications.
\end{abstract}

Key words: Antibacterial activity, Cerium oxide nanoparticles, Green capping agent, Humidity measurement

\section{INTRODUCTION}

Cerium oxide or ceria $\left(\mathrm{CeO}_{2}\right)$ is a lanthanide rare earth metal oxide having face centred cubic (FCC) fluorite type structure [1]. Nanoceria exists a cycle between the $\mathrm{Ce}^{3+}$ and $\mathrm{Ce}^{4+}$ valence states and it acts as a regenerative catalyst owed to the presence of oxygen vacancies [2]. In recent years the synthesis of nanoceria become more attention due to its outstanding properties such as large band gap energy $(3.19 \mathrm{eV})$, chemical stability, high thermal stability and dielectric properties $(\varepsilon=24.5)$ [3]. These properties of $\mathrm{CeO}_{2}$ enhance in wide spread of application like waste water treatment, bio-sensors, corrosion protection, photo catalytic efficiency, cosmetics and pharmaceuticals[1,4-8] Currently researchers focused on the antibacterial activity of cerium oxide nanoparticles $\left(\mathrm{CeO}_{2} \mathrm{NPs}\right)$ because of its excellent redox nature also it hinder the bacterial growth and scavenging free radicals [9]. Furthermore the non-aggregated NPs are very important to use in practical application, to achieve this expectation researchers will focused to reduce the aggregation of NPs during preparation process. In generally surfactants or capping agents are used to control the aggregation and agglomeration of metal oxides. In the case of $\mathrm{CeO}_{2} \mathrm{NPs}$ it is very difficult to control the aggregation because of its high surface energy and activity [10]. Fatemeh Sadat et.al reported that the agglomeration of nanoparticles were reduced using carbohydrate sugars as a capping agent [11]. From the literature study we decided to use sucrose as a green capping agent as it is eco-friendly, non-toxic, low cost and easily available.To the best of our knowledge no research work was done using sucrose as a capping agent for the preparation of $\mathrm{CeO}_{2}$ NPs by coprecipitation method. The foremost objective of this study is to find the structure, morphology, optical, humidity sensor and anti-bacterial studies of the synthesized $\mathrm{CeO}_{2} \mathrm{NPs}$.

\section{MATERIALS AND METHODS}

The chemicals used to prepare $\mathrm{CeO}_{2}$ NPs were analytical grade and used without further purification. Cerium ammonium nitrate $\mathrm{Ce}\left(\mathrm{NH}_{4}\right)_{2}\left(\mathrm{NO}_{3}\right)_{6}$, Sodium hydroxide $\mathrm{NaOH}$, Sucrose, Ethanol and deionised water used for all experiments. 


\subsection{Preparation of the sample}

In a typical procedure $0.1 \mathrm{M}$ of $\mathrm{Ce}\left(\mathrm{NH}_{4}\right)_{2}\left(\mathrm{NO}_{3}\right)_{6}$ solution was added to $0.1 \mathrm{M}$ of Sucrose solution. $0.03 \mathrm{M}$ of $\mathrm{NaOH}$ was added drop wise to the above solution with constant stirring to reach $\mathrm{PH}=11$. The clear solution turned yellowish after the reaction it was converted into light yellowish suspension. Thereafter the reaction continued for further $3 \mathrm{hrs}$ under magnetic stirring at room temperature. The final precipitate was washed several times with deionised water followed by ethanol. It was filtered and dried at $100^{\circ} \mathrm{C}$ for $4 \mathrm{hrs}$ to obtain pure $\mathrm{CeO}_{2} \mathrm{NPs}$, finally the powder was calcined at $500^{\circ} \mathrm{C}$ for $3 \mathrm{hrs}$.

\subsection{Characterization}

The prepared $\mathrm{CeO}_{2}$ NPs sample was characterized by the following techniques. The phase purity and crystallite size of the particles were analysed via Powder X-ray diffraction studies (XRD). The morphology and microstructure of $\mathrm{CeO}_{2}$ NPs were confirmed by SEM and TEM techniques. The optical properties and functional group identification was done through UV-vis, PL emission and FTIR spectroscopy respectively.

\subsection{Humidity sensor measurement}

The method was followed as we mentioned in our earlier published work in Elsevier [12]. The controlled humidity was attained in different humidity environments such as anhydrous (5\%) $\mathrm{P}_{2} \mathrm{O}_{5}, \quad(20 \%)$ CH3COOK, (31\%) $\mathrm{CaCl} 2$. $6 \mathrm{H} 2 \mathrm{O}$, (42\%) $\mathrm{Zn}(\mathrm{NO} 3) 2.6 \mathrm{H} 2 \mathrm{O}$, (51\%) NaNO2, (66\%) $\mathrm{NH} 4 \mathrm{Cl},(79 \%) \quad \mathrm{BaCl} 2.2 \mathrm{H} 2 \mathrm{O}$ and $(98 \%)$ CuSO4. 5H2O.The sensor element prepared with a fabricated pellet $(10 \mathrm{~mm}$ diameter and $1 \mathrm{~mm}$ thickness) consist of copper wire on both sides, the powder sample was dissolved in ethanol then dispensed on the pellet which dried at room temperature, finally it was kept at the above humidity environments to measure the sensitivity of the sample. The variation of dc resistance with relative humidity (RH 5-98\%) was measured with the help of barigo hygrometer.

\subsection{Antibacterial assay}

The antibacterial activity of the $\mathrm{CeO}_{2}$ NPs was examined by agar well diffusion method against three bacterial pathogens Staphylococcus aureus, Escherichia coli and Pseudomonuas aeruginosa at different concentration of the samples. The stock bacterial culture was stored at 4
${ }^{0} \mathrm{C}$, the active culture was prepared by transferring a loop of stock culture to the nutrient broth which was incubated at $37{ }^{\circ} \mathrm{C}$ for $24 \mathrm{hrs}$ and the turbidity was adjusted to Man Farland 0.5. Muller- Hinton agar was poured into the petriplates aseptically it was allowed to solidify, the lawns were made by sterile cotton and the wells were cuts with the help of sterile cork borer. The sample extract at different concentration $1.56,3.125,6.25,12.5,25$ and 50 $\mathrm{mg} / \mathrm{ml}$ was poured into the wells, finally the plates were incubated aerobically at $37{ }^{\circ} \mathrm{C}$ for $24 \mathrm{hrs}$. Afterward the antibacterial activity was estimated by measuring the inhibition zone formed around the well.

\section{RESULTS AND DISCUSSION}

\subsection{XRD studies}

The phase identification and crystalline size of as synthesized cerium oxide nanoparticles $\left(\mathrm{CeO}_{2} \mathrm{NPs}\right)$ were characterized by Powder X-ray diffraction pattern as shown in Fig.1. It reveals the four diffraction peaks corresponse to the cubic phase of $\mathrm{CeO}_{2}$ at $2 \theta$ angle $=29.10^{\circ}(111), 31.46^{\circ}$ (200), $48.95^{\circ}(220)$ and $54.68^{\circ}$ (311) respectively. All the diffraction peaks were indexed to cubic phase of $\mathrm{CeO}_{2}$ having cell parameter $\mathrm{a}=5.411 \mathrm{~A}^{0}$ belong to $F m \overline{3} \mathrm{~m}$ space group and also well matched with (JCPDS Card No: 34-394). The crystallite size of the sample was calculated using Scherrer's equation:

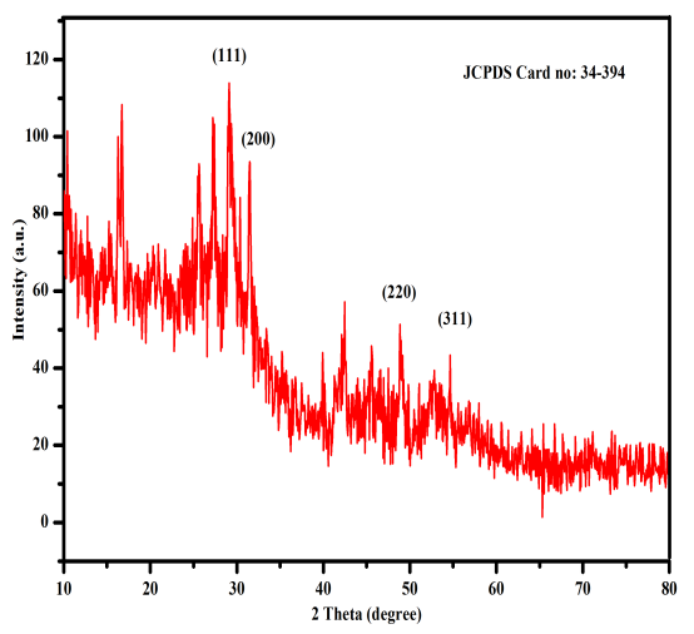

Fig.1. Powder XRD analysis of as synthesized $\mathrm{CeO}_{2}$ NPs.

$$
\mathrm{D}=0 \lambda / \beta h k l \cos \theta
$$




\section{Available online at $w w w . i j r a t . o r g$}

Where $\mathrm{D}$ is the crystallite size, $\beta$ is the full width half maximum (FWHM), $\theta$ is the diffraction angle and $\lambda$ is the wavelength of the incident $\mathrm{X}$ ray. The calculated crystallite size of sample was $29.05 \mathrm{~nm}$ for the most predominent peak at $2 \theta=$ $29.10^{\circ}(111)$ with $d$ space value of $3.068 \mathrm{~A}^{0}$. The development of the sharp peaks in the spectrum suggested the good crystallinity of the $\mathrm{CeO}_{2}$ NPs.

\subsection{FTIR spectroscopy}

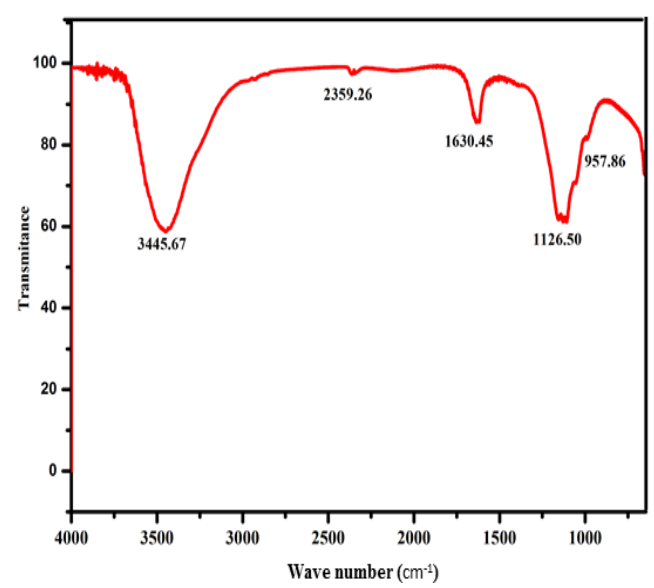

Fig.2. FTIR Spectrum of as synthesized $\mathrm{CeO}_{2} \mathrm{NPs}$.

The bonding nature and the presence groups were observed through FT-IR spectrum as shown in Fig.2. In this spectrum, the absorption bands appeared at 957, 1126, 1630, 2359 and 3445 $\mathrm{cm}^{-1}$, established the existence of pure $\mathrm{CeO}_{2}$ phase. Additionally the bands below $1000 \mathrm{~cm}^{-1}$ is ascribed to stretching vibration of $\mathrm{Ce}-\mathrm{O}$ [13]. The band located at the region of 1630 and $3445 \mathrm{~cm}^{-1}$ are assigned to bending and stretching vibrations of $\mathrm{OH}$ group present on the surface of $\mathrm{CeO}_{2} \mathrm{NPs}$. The bands near $1126 \mathrm{~cm}^{-1}$ is attributed to the presence of C-O-H group, which confirms the electrostatic force between sucrose chains and $\mathrm{CeO}_{2} \mathrm{NPs}$.

\subsection{Morphological studies}

The surface morphology and size of the $\mathrm{CeO}_{2}$ NPs were examined by Scanning electron microscopy (SEM). Fig.3 shows the bunches of small spherical particles at different magnification and it clearly displays that the agglomeration of the $\mathrm{CeO}_{2} \mathrm{NPs}$ was reduced by green capping agent used in the preparation process, however the images specifies high porosity on the surface of the $\mathrm{CeO}_{2}$ NPs which enhances the sensitivity of the sample.

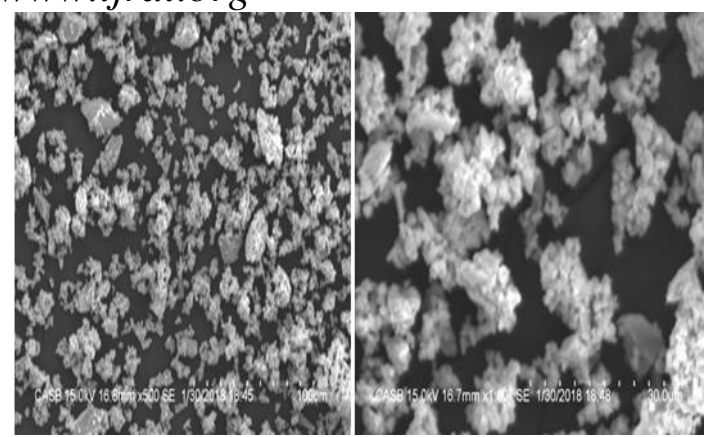

Fig.3. SEM images of $\mathrm{CeO}_{2} \mathrm{NPs}$.

Further, the microstructure and size of the $\mathrm{CeO}_{2}$ NPs was determined by TEM technique. Fig.4 reveals the corresponding selected area electron diffraction pattern (SAED) of the sample at 0.01 $\mathrm{nm}$, it exhibits the diffraction ring of cubic fluorite structure and the spots indicates the high degree of crystallinity of $\mathrm{CeO}_{2}$ NPs [14]. The bright spots confirms the formation of plane (111) with d space value of $3.068 \mathrm{~A}^{0}$, In addition it is well matched with XRD and SEM results.

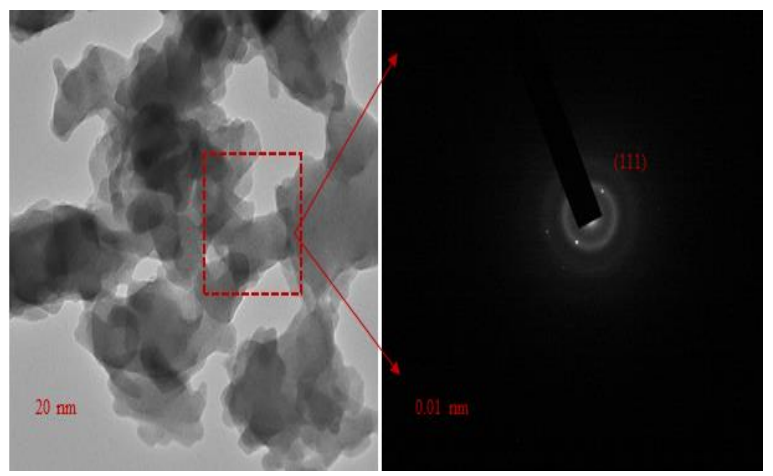

Fig.4. TEM images of $\mathrm{CeO}_{2} \mathrm{NPs}$

\subsection{Optical studies}

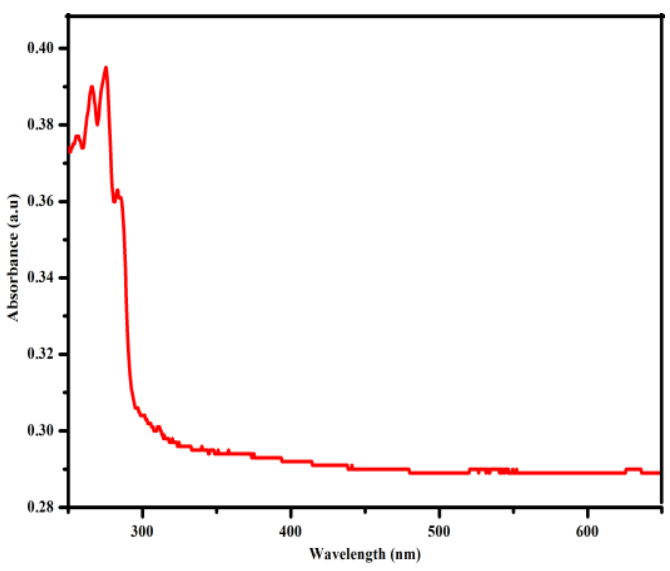

Fig.5a UV-vis absorption spectroscopy 
Fig.5a displays the UV-visible spectroscopy and it exhibits the absorption peak at $283.76 \mathrm{~nm}$. It shows better optical property, whereas the presence of the peak at $283.76 \mathrm{~nm}$ relates the quantum size effect of blue shift and confirms the charge transition takesplace between the $\mathrm{O} 2 \mathrm{p}$ and $\mathrm{Ce} 4 \mathrm{f}$ states in $\mathrm{O}^{2-}$ and $\mathrm{Ce}^{4+}[15,16]$. The band gap energy of the particles was calculated using Tauc's equation shown in Fig 5 b.

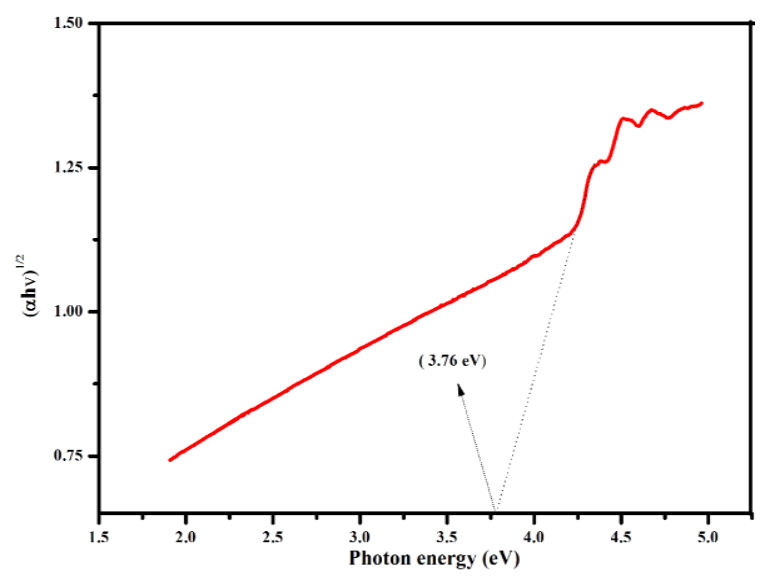

Fig.5b. Band energy plot of $\mathrm{CeO}_{2}$ NPs by Tauc's equation.

The extrapolation of stright line on energy axis (hv) will give direct band gap and it was found to be $3.76 \mathrm{eV}$, which is well contest with reported value $3.78 \mathrm{eV}$ for Cerium oxide [17] and it is higher band gap value than bulk $\mathrm{CeO}_{2}(3.19 \mathrm{eV})$.

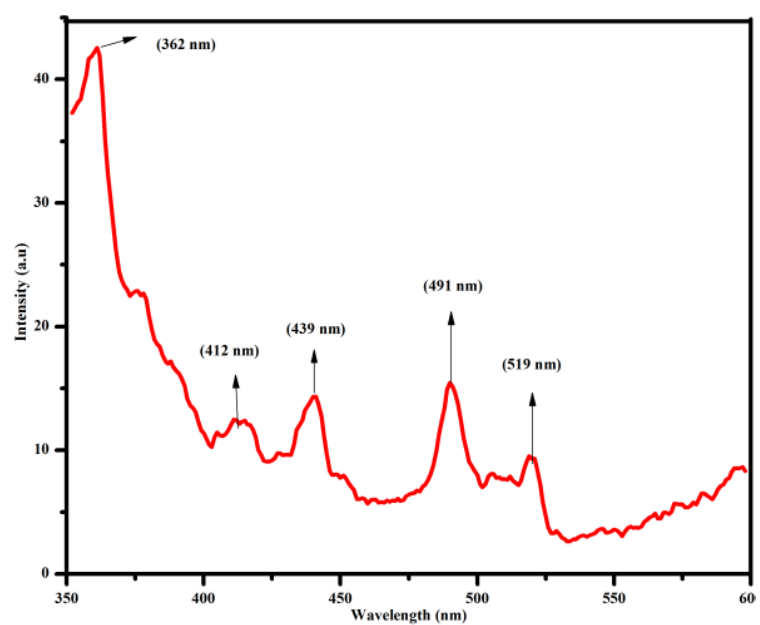

Fig. 6. displays photoluminescence spectra of $\mathrm{CeO}_{2}$ NPs.

Fig.6 shows the PL emission spectra of $\mathrm{CeO}_{2} \mathrm{NPs}$ excited at $350 \mathrm{~nm}$ and the spectrum displays multiple emission peak. The weak UV emission peak centered at the region of $362 \mathrm{~nm}$ is corresponds to band edge emission, a weak blue emissions peak at $412 \mathrm{~nm}$ is ascribed to the presence of surface defects. The blue emission peak centered at $439 \mathrm{~nm}$ is assigned to high level transition in $\mathrm{CeO}_{2}$ NPs. The weak blue-green emission peak at $491 \mathrm{~nm}$ can be attributed to the formation of oxygen vacancies during the preparation of the sample. Finally the broad green emission peak centered at $519 \mathrm{~nm}$ is due to the radiative recombination of excitions and the surface defects are excisting between Ce the inner $4 \mathrm{f}-5 \mathrm{~d}$ transition and $\mathrm{O} 2 \mathrm{p}$ valence state [18].

\subsection{Antibacterial studies}

The antibacterial activity of $\mathrm{CeO}_{2} \mathrm{NPs}$ was done in three bacterial species staphylococcus aureus, pseudomonuas aeruginosa and Escherichia coli by Agar well diffusion method under six different concentration of the sample as shown in Fig.7a.

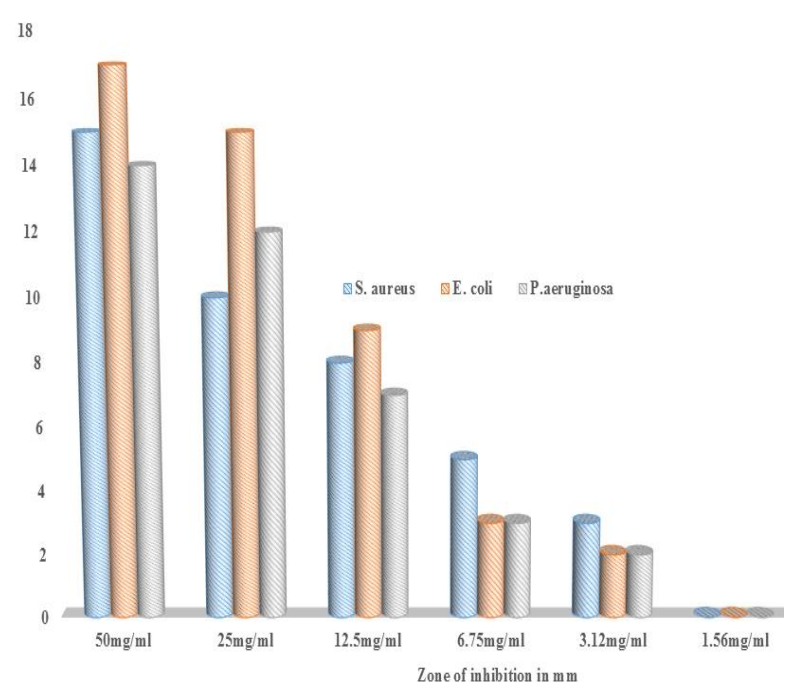

Fig.7a Diameter of the zone of inhibition of the micro-organism at different concentration of $\mathrm{CeO}_{2}$ NPs.

The results shows that the $\mathrm{CeO}_{2} \mathrm{NPs}$ possess higher antibacterial activity against Escherichia coli compared to the other two bacterial pathegons. At high concentration $50 \mathrm{mg} / \mathrm{ml}$ Escherichia coli possess higher $(17 \mathrm{~mm})$ zone of inhibition, however it is observed low in pseudomonuas aeruginosa. All the bacterial pathegons didn't show activity at lower concentration $1.56 \mathrm{mg} / \mathrm{ml}$ of the sample.Table. 1 shows that the zone of inhibition was increased with sample concentration.

Infact the larger surface area of the nanoparticles enhance the oxygen vacancies, passage of highly reactive molecules due to 
porosity. The good crystalline nature of the sample enhance the formation of reactive oxygen species [19]. In our studies the positively charged $\mathrm{CeO}_{2}$ NPs react with negatively charged cell membrane of given bacteria owing to electrostatic interaction finally it leads to bacterial death [20]. Also the diameter of zone of inhibition of bacterial species was observed in the order of Escherichia coli > pseudomonuas aeruginosa > pseudomonuas aeruginosa.

\subsection{Humidity sensor studies}

Fig.8a shows the change in resistance log $\mathrm{R}$ with relative humidity $\mathrm{RH} \%$ of $\mathrm{CeO}_{2} \mathrm{NPs}$ measured at room temperature. Humidity sensor operating at room temperature having the advantage of protonic conduction on the surface of the semi-conduction materials. The presence of high porosity nature on the surface of $\mathrm{CeO}_{2} \mathrm{NPs}$
The plot of $\log \mathrm{R}$ vs RH\% shows a linear curve, also decrease in resistance at 5-98\% of $\mathrm{RH}$ for $\mathrm{CeO}_{2}$ NPs. The sensitivity factor $\mathrm{S}_{\mathrm{f}}$ was calculated by $\mathrm{R}_{5 \%} / \mathrm{R}_{98 \%}$, where $\mathrm{R}_{5 \%}$ and $\mathrm{R}_{98 \%}$, are $\mathrm{dc}$ resistance at RH $5 \%$ and $\mathrm{RH} 98 \%$. The calculated $S_{f}$ value was found to be $S_{f}=2876$, however the higher value of $S_{f}$ raise the sensitivity of sample towards a moisture [22].The response and recovery time was studied and the graph of $\log \mathrm{R}$ vs Time was measured for RH 5\% and RH $98 \%$ as shown in Fig. $8 \mathrm{~b}$. The response and recovery time was found to be $45 \mathrm{~s}$ and $197 \mathrm{~s}$ respectively. The observed results conclude that the stability of $\mathrm{CeO}_{2} \mathrm{NPs}$ is appreciable to utilise in sensor applications.

Table.1 Diameter of Zone of inhibition in $\mathrm{mm}$

\begin{tabular}{|c|c|c|c|c|c|c|}
\hline \multirow{2}{*}{ Micro-organism } & \multicolumn{6}{|c|}{ Zone of inhibition in mm } \\
\cline { 2 - 7 } & $50 \mathrm{mg} / \mathrm{ml}$ & $25 \mathrm{mg} / \mathrm{ml}$ & $12.5 \mathrm{mg} / \mathrm{ml}$ & $6.75 \mathrm{mg} / \mathrm{ml}$ & $3.12 \mathrm{mg} / \mathrm{ml}$ & $1.56 \mathrm{mg} / \mathrm{ml}$ \\
\hline $\begin{array}{c}\text { Staphylococcus } \\
\text { aureus }\end{array}$ & 15 & 10 & 8 & 5 & 3 & Nil \\
\hline $\begin{array}{c}\text { Escherichia coli } \\
\text { Pseudomonuas } \\
\text { aeruginosa }\end{array}$ & 17 & 15 & 9 & 3 & 2 & Nil \\
\hline
\end{tabular}

Nil = No antibacterial activity.

encourage the change in resistance with relative humidity level due to adsorption and capillary condensation [21].

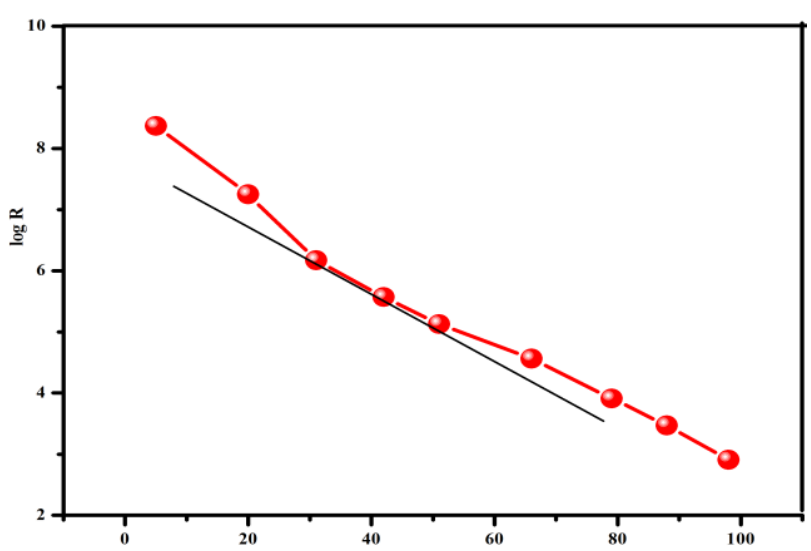

Fig.8a. Humidity selrsor meredistriement, a plot of log R Vs RH.

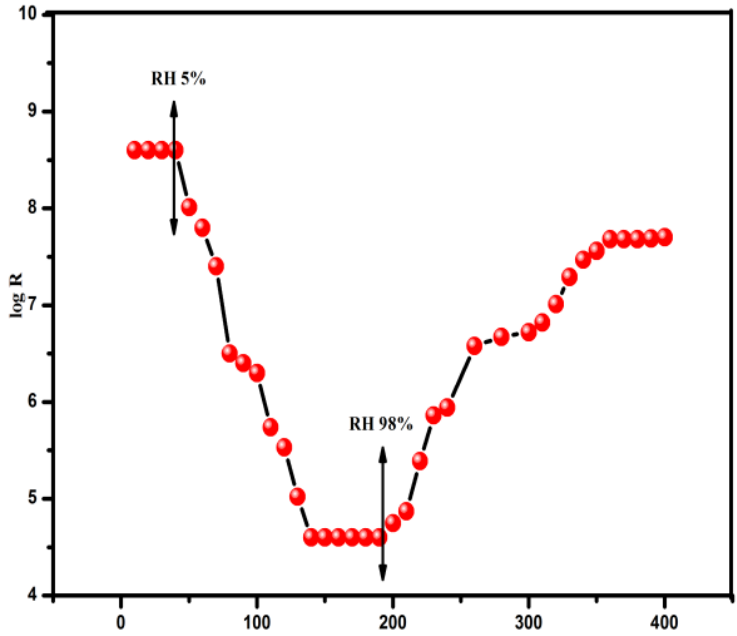

Fig. 8b. Response and réco Timesery measurement, a plot of $\log$ R Vs Time (sec). 


\section{International Journal of Research in Advent Technology, Vol.7, No.2, February 2019 E-ISSN: 2321-9637 \\ Available online at $w w w . i j r a t . o r g$}

\section{CONCLUSION}

We conclude that the samples were successfully prepared by simple co-precipitation method. The XRD pattern determined the formation of cubic phase of $\mathrm{CeO}_{2}$ with crystallite size of $29.05 \mathrm{~nm}$. The $\mathrm{CeO}_{2}$ NPs exhibits bunches of small spherical like morphology with high porosity. The samples exhibits the multiple emission peaks centred at $362,412,439,491$ and $519 \mathrm{~nm}$ and the calculated band gap $3.76 \mathrm{eV}$. The humidity sensing measurement illustrates $\mathrm{CeO}_{2}$ NPs highest sensitivity factor $S_{\mathrm{f}}=2876$ with response time of $45 \mathrm{~s}$ and recovery time of $197 \mathrm{~s}$ respectively. The antibacterial studies of $\mathrm{CeO}_{2}$ NPs reveals encouraging antibacterial activity against both Gram- positive and Gram-negative bacteria.

\section{Acknowledgement}

This research work is supported by Maulana Azad National Fellowship (MANF), UGC-MHRD, Govt. of India, and New Delhi through SRF grant No.F.17.1/2016/MANF-201517-TAM-62835/ (SA-III/website).

I am very much thankful to Dr. SK. Jasmine Shahina, Asst.Prof and Summera Rafiq, Associate Prof \& HOD, Dept. of Microbiology, JBAS College for Women (Autonomous), Teynampet, Chennai-18. For extending the Lab facilities to do antibacterial studies.

\section{REFERENCES}

[1] S. K. Kannan and M. Sundrarajan, "A Green Approach for the synthesis of a Cerium Oxide Nanoparticle: Characterization and Antibacterial Activity", International Journal of Nanoscience, Vol. 13(3), pp. 1450018, 2014.

[2] E. G. Heckert, A. S. Karakoti, S. Seal and W. T. Self, "The role of cerium redox state in the SOD mimetic activity of nanoceria", Biomaterials, Vol. 29 (18), pp. 2705-2709, 2008.

[3] J. J. Miao, H. Wang, Y. R. Li, J. M. Zhu and J. J. Zhu, "Ultrasonic induced synthesis of $\mathrm{CeO}_{2}$ nanotubes, J.Cryst. Growth, Vol. 281, pp. 525529,2005

[4] S. Thakur and P. Patil, " Rapid synthesis of cerium oxide nanoparticles with superior humidity- sensing performance, Sens. Actuator B, Vol. 194, pp. 260-268, 2014.

[5] Y. Xingwen, C. Chunan, Y. Zhiming, Z. Derui and Y. Zhungda, Corrosion Science, Vol. 43, pp. 1283-1294, 2001.

[6] B.Li, T. Gu, T. Ming, J. Wang, P. Wang and J. C. Yu, " Gold Core@ Ceria Shell nanostructures for plasmon-enhanced catalytic creations under visible light", ACS Nano, Vol. 8, pp. 8152-8162, 2014.

[7] Toshiyuki Masui, Hidekazu Hirai, Ryo Hamada, Nobuhito Imanaka, Gin-ya Adachi, Takao Sakatac and Hirotaro Moric, "Synthesis and characterization of cerium oxide nanoparticles coated with turbostratic boron nitride", J. Mater. Chem, Vol. 13, pp. 622-627, 2003.

[8] A. Thill, O. Zeyons, O. Spalla, F. Chauvat, J. Rose, M. Auffan and A. M. Flank, "Cytotoxicity of $\mathrm{CeO}_{2}$ nanoparticles for Escherichia coli. Physico-chemical insight of the cytotoxicity mechanism", Environ. Sci. Technol, Vol. 40, pp. 6151-6156, 2006.

[9] S. Babu, A. Velez, K. Wozniak, J. Szydlowska and S. Seal, "Electron paramagnetic study on radical scavenging properties of ceria nanoparticles", Chem Phys Lett, Vol. 442, pp. 405-408, 2007.

[10] Kang-Qiang Liu, Cheng-Xiu Kuang, MingQiang Zhong, Yan-Qin Shi and Feng Chen, "Synthesis, characterization and UV-shelding property of polystyrene-embedded $\mathrm{CeO}_{2}$ nanoparticles", Optical Materials, Vol. 35, pp.2710-2715, 2013.

[11] Fatemeh Sadat Sangsefidi, Majid Nejati, Javad Verdi and Masoud Salavati- Niasari, "Green synthesis and characterization of cerium oxide nanostructures in the presence carbohydrate sugars as a capping agent and investigation of their cytotoxicity on the mesenchymal stem cell", Journal of Cleaner Production, Vol. 156, pp. 741-749, 2017.

[12] A. Mobeen Amanulla, SK. Jasmine Shahina, R. Sundaram, C. Maria Magdalane, K. Kaviyarasu, Douglas Letsholathebe, S. B. Mohamed, J. Kennedy and M. Maaza, "Antibacterial, magnetic, optical and humidity sensor studies of $\beta-\mathrm{CoMoO}_{4}-\mathrm{Co}_{3} \mathrm{O}_{4}$ nanocomposites and its synthesis and characterization", Journal of Photochemistry B: Biology, Vol. 183, pp. 233-241, 2018.

[13] M. K. Amosa, "Process optimization of Mn and $\mathrm{H}_{2} \mathrm{~S}$ removals from POME using an enhanced empty fruit bunch (EFB) - based adsorbent produced by pyrolysis", Environ. Nanotechnol. Monit. Manage, Vol. 4, pp. 93105, 2015.

[14] S. Phoka, P. Laokul, E. Swatsitang, S. Promarak and Maensiri, Mater. Chem. Phys, Vol. 115, pp. 423-428, 2009.

[15] S. B. Khan, M. Faisal, M. M. Rahman and A. Jamal, "Exploration of $\mathrm{CeO} 2$ nanoparticles as a chemi-sensor and photo-catalyst for 
environmental applications", Sci. Total Environ, Vol. 409, pp. 2987-2992, 2011.

[16] M. Darroudi, S. J. Hoseini, R. K. Oskuee, H. A. Hosseini, L. Gholami and Gerayali, Ceram. Int, Vol. 40, pp. 7425, 2014.

[17] K. Sabzevari, H. Adibkia, A. Hashemi, N. Hedayatfar, F. Mohsenzadeh , Atyabi, et.al, "Polymeric triamcinolone acetonide nanoparticles as a new alternative in the treatment of uveitis: In vitro and in vivo studies", Eur. J. Pharm. Biopharm, Vol. 84, pp. 63-71, 2013.

\section{High lights}

[18] S. Maensiri, S. Labuayai, J. Laokul, Klinkaewnarong and E. Swatsitang, Jpn. J. Appl. Phys, Vol. 53, pp. 06-14, 2014.

[19] P. Singh and A. Nanda, "Enhanced sun protection of nano-sized metal oxide particles over conventional metal oxide particles: An in vitro comparative study", Int. J. Cosmetic Sci, Vol. 36, pp. 273-283, 2014.

[20] Y. R. Gao and Cranston, Textile Research Journal, Vol. 78, pp. 60-72, 2008.

[21] S. Neeraj, N. Kijima, and A. K. Cheetham, Chem. Phys. Lett, Vol. 387, pp. 2-6, 2004.

[22] S. Pokhrel and K. S. Nagaraja, Phy. Stat. Sol. A, Vol. 343, 2003.

- Simple method of preparation, non-toxic, using green capping agent.

- Cubic phase of $\mathrm{CeO}_{2}$ with crystallite size of $29.05 \mathrm{~nm}$.

- Bunches of small spherical like morphology with high porosity, band gap $3.76 \mathrm{eV}$.

- Highest sensitivity factor $\mathrm{S}_{\mathrm{f}}=2876$.

- Encouraging antibacterial activity against micro-organisms. 